\title{
Hodgkin lymphoma in pregnancy - current management practice based on case report series
}

\author{
Renata Kroll-Balcerzak, Marta Baranska, Lidia Gil, \\ Maciej Kazmierczak, Andrzej Balcerzak, Dariusz Izycki
}

Department of Hematology and Bone Marrow Transplantation, Poznan University of Medical Sciences, Poznan, Polska

\section{Introduction}

Despite numerous publications discussing the problem, the effects of pregnancy on the progress of malignancy and its prognosis, the effects of the disease and the applied therapy on the foetus, the optimal timing of chemotherapy and possible necessity for early termination of pregnancy raise controversies. Hodgkin lymphoma (HL) affects one in 1000-6000 pregnancies. The treatment of choice is chemotherapy combined with radiotherapy has become established international standards of care for advanced $\mathrm{HL}$.

\section{Objectives}

Prognosis in patients with $\mathrm{HL}$ during pregnancy resembles that observed in non-pregnant women, provided that proper therapeutic management is applied. There are no prospective trials for the management of $\mathrm{HL}$ in pregnancy, but a number of published case reports, case series and case cohorts were reviewed earlier.

\section{Material and methods}

Nine pregnant patients at the age of 20 and 28 (median 24.1), with Hodgkin lymphoma treated between 1997 and 2014 in the Department of Hematology and Bone Marrow Transplantation Poznan University of Medical Sciences, were enrolled in this study. HL was diagnosed between 11th and 30th week of pregnancy on the basis of histopatological evaluation of the excised lymph node. We determined the clinical stage according to the Ann Arbor classification modified in Cotswolds. Characteristics of the examined group, regiment of chemotherapy applied, type of clinical response and performance status of newborns after birth are showed in Table 1.

\section{Results and conclusions}

Our study of the group of 9 patients confirmed high safety of using ABVD chemotherapy in patients with Hodgkin lymphoma, either in the early or in late period of pregnancy. Analysis of various clinical cases presented above confirms high efficacy and safety of the applied antineoplastic treatment in pregnant patients with HL. An effort should be made to determine the stage of the disease and presence of unfavourable prognostic factors precisely. 


\begin{tabular}{|c|c|c|c|c|c|c|c|c|c|c|}
\hline Item & Patient age [years] & $\begin{array}{l}\text { Trimester of } \\
\text { pregnancy }\end{array}$ & $\begin{array}{l}\text { HL } \\
\text { type }\end{array}$ & CS* & IPS & Applied treatment & $\begin{array}{l}\text { Result of } \\
\text { treatment }\end{array}$ & $\begin{array}{l}\text { Delivery } \\
\text { [week] }\end{array}$ & $\begin{array}{l}\text { Apgar } \\
\text { score }\end{array}$ & $\begin{array}{l}\text { Birth } \\
\text { weight [g] }\end{array}$ \\
\hline 1. & 28 & 1 & MC & $\| A$ & 2 & $\begin{array}{l}4 \times \text { ABVD } \\
\text { unexpected pregnancy } \\
4 \times \text { ABVD } \\
2 \times \text { ESHAP } \\
2 \times \text { IVE } \\
\text { auto-HSCT } \\
\text { relapse } \\
3 \times \text { GDP } \\
\text { auto-HSCT }\end{array}$ & $\begin{array}{l}\text { PR } \\
\text { PR } \\
\text { Progression } \\
\text { PR } \\
\text { CR } \\
\text { CR } \\
\text { CR }\end{array}$ & 40 & 10 & 3400 \\
\hline 2. & 23 & II & NS & IIIA & 1 & $8 \times A B V D$ & $C R$ & 32 & 8 & 1800 \\
\hline 3. & 22 & II & MC & $\| \mathrm{B}$ & 2 & $7 \times A B V D$ & $\mathrm{CR}$ & 37 & 10 & 3100 \\
\hline 4. & 24 & II & NS & IIIIB & 2 & $8 \times A B V D$ & $C R$ & 36 & 10 & 2900 \\
\hline 5. & 25 & II & NS & IVA & 5 & $\begin{array}{l}\text { abortion } \\
8 \times \text { ABVD } \\
\text { diagnosis of pregnancy } \\
2 \times \text { DHAP }\end{array}$ & $\begin{array}{l}\text { PR } \\
\text { CR }\end{array}$ & 36 & 10 & 2800 \\
\hline 6. & 26 & II & NS & IVB & 5 & $\begin{array}{l}\text { ABVD } 6 x \\
\text { ESHAP } 3 x \\
\text { auto-HSCT }\end{array}$ & $\begin{array}{l}\text { resistance } \\
C R \\
C R\end{array}$ & 36 & 10 & 2700 \\
\hline 7. & 25 & ॥ & NS & IVB & 3 & $4 \times$ BEACOPP & $C R$ & 38 & 8 & 3100 \\
\hline 8. & 24 & II & NS & IVB & 2 & $8 \times A B V D$ & $C R$ & 38 & 10 & 3200 \\
\hline 9. & 20 & II & NLPHL & IVB & 3 & $\begin{array}{l}4 \times \text { ABVD } \\
2 \times \text { BEACOPP }\end{array}$ & $\begin{array}{l}\text { PR } \\
C R\end{array}$ & 38 & 10 & 3400 \\
\hline
\end{tabular}

HL - Hodgkin lymphoma; MC - mixed cellularity; NS - nodular sclerosis; NLPHL — lymphocyte-predominant Hodgkin lymphoma; CS - clinical stage; IPF — International Prognostic Score; PR - partial remission; CR complete remission; ABVD — doxorubicin, bleomycin, vinblastine, dacarbazine; BEACOPP — bleomycin, etoposide, adriamycin, cyclophosphamide, vincristine, procarbazine, prednisone; ESHAP — etoposide, methylprednisolone, cytarabine, cisplatin; IVE — ifosfamide, epirubicin, etoposide; GDP - gemcitabine, dexamethasone, cisplatin; auto-HSCT — autologous hematopoietic stem cell transplantation

* clinical stage according to Ann Arbor classification modified in Cotswolds 